\title{
Gambaran fungsi kognitif pada penderita hipertensi di Kelurahan Kakaskasen III Kecamatan Tomohon Utara periode September-Oktober 2016
}

\author{
${ }^{1}$ Janiffer F. Watulingas \\ ${ }^{2}$ Mieke A. H. N.Kembuan \\ ${ }^{2}$ Winifred Karema
}

\author{
${ }^{1}$ Kandidat Skripsi Fakultas Kedokteran Universitas Sam Ratulangi Manado \\ ${ }^{2}$ Bagian Neurologi Fakultas Kedokteran Universitas Sam Ratulangi Manado \\ Email: janiffer.watulingas@yahoo.com
}

\begin{abstract}
Hypertension is a desease that occurs due to increased blood pressure. Hypertension is classified in two major types, primary hypertension which cause is still unknown and secondary hypertension caused by renal disease, endocrine disease, heart disease, etc. Although hypertension usually does not show up any symptom, as the blood pressure keeps increasing it could lead to a serious complication. Due to that reason, hypertension has to be detected early by doing a periodical check-up of blood pressure. In daily life, cognitive function in hypertension patients is less needed. Hypertension itself is one of the risk factors of cardiovascular disease that shows an existence of the correlation between the risk factors themselves and the decline of cognitive function. MMSE examination showed that $42.50 \%$ of the respondens had cognitive impairment meanwhile CDT examination showed that $47.50 \%$ of the respondents had cognitive impairment.
\end{abstract}

Keywords: hypertension, MMSE, CDT, Cognitive function.

\begin{abstract}
Abstrak: Hipertensi merupakan penyakit yang terjadi akibat adanya peningkatan tekanan darah. Hipertensi biasa diklasifisikan menjadi 2 jenis, hipertensi primer yang penyebabnya tidak diketahui dan hipertensi sekunder yang disebabkan oleh penyakit ginjal, penyakit endokrin, penyakit jantung,dll. Hipertensi biasanya tidak menimbulkan gejala, dan sementara tekanan darah terus menerus menigkat dan dalam jangka waktu lama bisa menyebabkan komplikasi. Oleh karena itu hipertensi sebaiknya harus dideteksi dini dengan melakukan pemeriksaan tekanan darah secara berkala. Dalam keseharian fungsi kognitif pada penderita hipertensi kurang diperhatikan dan akan diperhatikan jika penderita hipertensi telah mengalami stroke. Hipertensi sendiri ialah salah satu faktor resiko penyakit kardiovaskular yang menunjukkan adanya hubungan faktor risiko tersebut dengan penurunan fungsi kognitif. Hasil pemeriksaan fungsi kognitif pada penderita hipertensi menggunakan MMSE mendapatkan bahwa yang mengalami gangguan kognitif sebesar $42,50 \%$ sedangkan pada pemeriksaan menggunakan CDT didapatkan yang mengalami gangguan kognitif sebesar $47,50 \%$.
\end{abstract}

Kata kunci: hipertensi, MMSE, CDT, fungsi kognitif.

Hipertensi merupakan penyakit yang terjadi akibat adanya peningkatan tekanan darah. Hipertensi biasa diklasifisikan menjadi 2 jenis, hipertensi primer yang penyebabnya tidak diketahui dan hipertensi sekunder yang disebabkan oleh penyakit ginjal, penyakit endokrin, penyakit jantung, dll. Hipertensi biasanya tidak menimbulkan gejala, dan sementara tekanan darah terus menerus menigkat dan dalam jangka waktu lama bisa menyebabkan komplikasi. Oleh karena itu hipertensi sebaiknya harus 
dideteksi dini dengan melakukan pemeriksaan tekanan darah secara berkala. ${ }^{1}$ Kesadaran masyarakat untuk melakukan kontrol tekanan darah masih jauh dari yang diharapkan. Hal ini kemungkinan disebabkan karena meningkatnya tekanan darah tidak menunjukan gejala-gejala, disamping kurangnya pengetahuan tentang factor resiko meningkatnya tekanan darah tersebut. Saat ini hipertensi merupakan tantangan besar di Indonesia karena merupakan kondisi yang sering ditemukan pada pelayanan kesehatan primer. Berdasarkan survei riset dasar kesehatan nasional (RISKESDAS) pada tahun 2013 hipertensi memiliki prevalensi yang tinggi, yaitu sebesar 25,8\%. Disamping itu pengontrolan hipertensi belum adekuat meskipun sudah banyak tersedia obatobatan yang efektif., ${ }^{2,3}$

Dalam keseharian kita biasanya fungsi kognitif pada penderita-penderita hipertensi kurang diperhatikan dan yang biasa akan diperhatikan jika penderita hipertensi telah mengalami stroke. Hipertensi sendiri merupakan salah satu faktor risiko penyakit kardiovaskular yang menunjukkan adanya hubungan faktor resiko tersebut dengan penurunan fungsi kognitif. Menurut hasil penelitian lainnya, terdapat $12,3 \%$ mengalami gangguan kognitif yang disebabkan karena tekanan darah tinggi. Di Indonesia menurut data dari KEMENKES tahun 2012 bahwa prevalensi penderita hipertensi yang mengalami penurunan fungsi kognitif sebesar 7-9\%.,

Fungsi kognitif sendiri adalah merupakan kemampuan berpikir dan memberikan rasional, termasuk proses belajar, mengingat menilai, orientasi, persepsi dan memperhatikan. ${ }^{5}$ Dalam hal ini penulis tertarik untuk dapat mengetahui gambaran fungsi kognitif pada penderita hipertensi yang ada di Kelurahan Kakaskasen III, kec. Tomohon Utara.

Untuk melakukan atau menilai fungsi kognitif pada penderita hipertensi di Kelurahan Kakaskasen III, Kecamatan Tomohon Utara, maka akan digunakan the mini mental state examination (MMSE) dan clock drawing test (CDT) ,sebagai pemeriksaan yang dapat digunakan untuk mengevaluasi dan konfirmasi status fungsi kognitif. MMSE adalah pemeriksaan yang cepat untuk dilakukan, hanya berupa 30 point-test terhadap fungsi kognitif yang berisikan uji orientasi, memori kerja dan memori episodik, bahasa. Untuk CDT akang dilakukan tes kemampuan pemahaman, konsentrasi, pengetahuan angka, kemampuan visual spasial, ingatan visual. $^{6}$

\section{METODE PENELITIAN}

Penelitian ini adalah penellitian potong lintang (cross sectional) yang bersifat deskriptif dengan data primer untuk mengetahui gambaran fungsi kognitif pada penderita hipertensi. Penelitian dilakukan di Kelurahan Kakaskasen III, Kec. Tomohon Utara periode september-oktober 2016. Pasien yang diambil menjadi sampel adalah yang memenuhi kriteria, yaitu pasien yang mempunyai riwayat hipertensi atau pasien yang menderita hipertensi.Variabel penelitian ini adalah usia, jenis kelamin, pendidikan, pekerjaan. Setelah data diambil maka pengolahan data dilakukan secara manual dengan mengelompokkan data yang telah diperoleh berdasarkan variable penelitian dan kemudian menghitung dalam bentuk distribusi variabel kemudian menyajikan data dalam bentuk tulisan, grafik, dan tabel frekuensi.

\section{HASIL PENELITIAN}

Dari hasil penelitian yang telah dilakukan pada penderita riwayat hipertensi di Kelurahan Kakaskasen III, Kec. Tomohon utara dengan menggunakan pemeriksaan Mini Mental State Examination (MMSE) dan Clock Drawing Test (CDT) untuk melihat fungsi kognitif pada 40 responden yang telah dipilih maka di dapatkan hasil:

Dari Tabel 1 dapat dilihat bahwa distribusi penderita dengan riwayat hipertensi berdasarkan jenis kelamin lebih banyak didapatkan pada perempuan yaitu sebanyak 26 orang $(65 \%)$ daripada laki-laki hanya berjumlah 14 orang (35\%). 
Tabel 1. Distribusi penderita berdasarkan jenis kelamin

\begin{tabular}{lll}
\hline Jenis kelamin & Jumlah & $\mathbf{( \% )}$ \\
\hline Laki - laki & 14 & 35 \\
Perempuan & 26 & 65 \\
Total & 40 & 100 \\
\hline
\end{tabular}

Tabel 2. Distribusi penderita berdasarkan usia

\begin{tabular}{ccc}
\hline Usia & Jumlah & $\mathbf{( \% )}$ \\
\hline $20-39$ & 5 & 12,5 \\
$40-59$ & 24 & 60 \\
$60-79$ & 9 & 22,5 \\
$\geq 80$ & 2 & 5 \\
Total & $\mathbf{4 0}$ & $\mathbf{1 0 0}$ \\
\hline
\end{tabular}

Dalam Tabel 2 dapat dilihat bahwa dari golongan usia didapatkan usia 40-59 tahun lebih banyak yaitu sebesar 24 orang $(60 \%)$ dan yang paling sedikit didapatkan pada golongan usia $>80$ tahun yang hanya 2 orang $(5 \%)$.

Tabel 3. Distribusi penderita berdasarkan tingkat pendidikan

\begin{tabular}{lcc}
\hline Pendidikan & $(\mathbf{n})$ & $\mathbf{( \% )}$ \\
\hline SD & 6 & 15 \\
SMP & 11 & 27,5 \\
SMA & 14 & 35 \\
>SMA & 9 & 22,5 \\
Total & $\mathbf{4 0}$ & $\mathbf{1 0 0}$ \\
\hline
\end{tabular}

Dari Tabel 3 didapatkan bahwa penderita dengan riwayat hipertensi paling banyak pada tingkat pendidikan SMA sebanyak 14 orang $(27,5 \%)$ dan yang paling sedikit yaitu pada tingkat SD sebanyak 6 orang (15\%) yang didapatkan.

Berdasarkan hasil Tabel 4 didapatkan bahwa penderita dengan riwayat hipertensi terbanyak pada golongan pekerjaan sebagai IRT dengan jumlah 14 orang $(35 \%)$ dan yang paling sedikit didapat pada golongan pekerjaan sebagai pensiunan sebanyak 2 orang $(5 \%)$.

Dari hasil penelitian yang telah didapatkan terhadap 40 responden dengan menggunakan Mini Mental State Examination (MMSE) dan Clock Drawing
Test (CDT) didapatkan dengan pemeriksaan MMSE yang termasuk dalam kategori normal sebanyak 23 orang $(57,5 \%)$ dan yang masuk dalam kategori dengan fungsi kognitif terganggu sebanyak 17 orang $(42,5 \%)$ (Tabel 5).

Tabel 4. Distribusi penderita berdasarkan pekerjaan

\begin{tabular}{lcc}
\hline Pekerjaan & Jumlah & $\mathbf{( \% )}$ \\
\hline Pedagang & 7 & 17,5 \\
PNS & 7 & 17,5 \\
TNI/Polri & 0 & 0 \\
Buruh/Tani & 6 & 15 \\
Pensiunan & 2 & 5 \\
Wiraswasta & 4 & 10 \\
IRT & 14 & 35 \\
Profesional & 0 & 0 \\
Total & 40 & 100 \\
\hline
\end{tabular}

Tabel 5. Pemeriksaan MMSE

\begin{tabular}{lcccc}
\hline MMSE & \multicolumn{4}{c}{ Norgal } \\
\cline { 2 - 5 } Variabel & $\mathbf{n}$ & $\mathbf{\%}$ & $\mathbf{n}$ & $\mathbf{\%}$ \\
\hline Jenis kelamin & & & & \\
Laki-laki & 9 & 22,5 & 5 & 12,5 \\
Perempuan & 14 & 35 & 12 & 30 \\
\hline Umur & & & & \\
20-39 & 5 & 12,5 & 0 & 0 \\
40-59 & 16 & 40 & 8 & 20 \\
60-79 & 2 & 5 & 7 & 17,5 \\
$\geq 80$ & 0 & 0 & 2 & 5 \\
\hline Pendidikan & & & & \\
SD & 2 & 5 & 4 & 10 \\
SMP & 6 & 15 & 5 & 12,5 \\
SMA & 6 & 15 & 8 & 20 \\
\cline { 2 - 5 }$>$ SMA & 9 & 22,5 & 0 & 0 \\
\hline Pekerjaan & & & & \\
Pedagang & 5 & 12,5 & 2 & 5 \\
PNS & 7 & 17,5 & 0 & 0 \\
TNI/Polri & 0 & 0 & 0 & 0 \\
Buruh/Tani & 0 & 0 & 6 & 15 \\
Pensiunan & 0 & 0 & 2 & 5 \\
Wiraswasta & 3 & 7,5 & 1 & 2,5 \\
IRT & 8 & 20 & 6 & 15 \\
Profesional & 0 & 0 & 0 & 0 \\
\hline
\end{tabular}

Dari hasil pemeriksaan CDT sesuai pada diagram yang termasuk dalam kategori normal sebanyak 21 orang $(52,5 \%)$ dan yang masuk dalam fungsi 
kognitif terganggu sebanyak 19 orang $(47,5 \%)$

Tabel 6. Pemeriksaan CDT

\begin{tabular}{|c|c|c|c|c|}
\hline \multicolumn{5}{|l|}{ CDT } \\
\hline \multirow[b]{2}{*}{ Variabel } & \multicolumn{2}{|c|}{ Normal } & \multicolumn{2}{|c|}{ Terganggu } \\
\hline & $\mathbf{n}$ & $\%$ & $\mathbf{n}$ & $\%$ \\
\hline \multicolumn{5}{|l|}{ Jenis } \\
\hline kelamin & 6 & 15 & 8 & 20 \\
\hline Laki-laki & 15 & 37,5 & 11 & 27,5 \\
\hline Perempuan & & & & \\
\hline \multicolumn{5}{|l|}{ Umur } \\
\hline $20-39$ & 3 & 7,5 & 2 & 5 \\
\hline $40-59$ & 15 & 37,5 & 9 & 22,5 \\
\hline $60-79$ & 3 & 7,5 & 6 & 15 \\
\hline$\geq 80$ & 0 & 0 & 2 & 5 \\
\hline \multicolumn{5}{|l|}{ Pendidikan } \\
\hline SD & 0 & 0 & 6 & 15 \\
\hline SMP & 4 & 10 & 7 & 17,5 \\
\hline SMA & 10 & 25 & 4 & 10 \\
\hline$>$ SMA & 7 & 17,5 & 2 & 5 \\
\hline \multicolumn{5}{|l|}{ Pekerjaan } \\
\hline Pedagang & 3 & 7,5 & 4 & 10 \\
\hline PNS & 5 & 12,5 & 2 & 5 \\
\hline TNI/Polri & 0 & 0 & 0 & 0 \\
\hline Buruh/Tani & 1 & 2,5 & 5 & 12,5 \\
\hline Pensiunan & 0 & 0 & 2 & 5 \\
\hline Wiraswasta & 4 & 10 & 0 & 0 \\
\hline IRT & 8 & 20 & 6 & 15 \\
\hline Profesional & 0 & 0 & 0 & 0 \\
\hline
\end{tabular}

\section{BAHASAN}

Penelitian ini dilakukan pada pasien dengan riwayat hipertensi di Kelurahan Kakaskasen III, Kecamatan Tomohon Utara dengan jumlah responden sebanyak 40 orang dan semua responden termasuk dalam kriteria yang ditentukan.

Dapat dilihat dari data yang telah didistribusi, pada gambaran jenis kelamin responden perempuan sebanyak 26 orang $(65 \%)$ dan responden laki-laki sebanyak 14 orang $(35 \%)$. Ini berarti bahwa jumlah responden yang memiliki riwayat hipertensi didapatkan lebih banyak pada perempuan dibandingkan laki-laki dari total jumlah responden sebanyak 40 orang. Hasil ini juga sesuai dengan prevalensi yang dilakukan dalam penelitian lain di RSUD dr. Zainoel Abidin Bandah Aceh yang dimana prevalensi perempuan lebih banyak yaitu sebesar 59,5\% dibandingkan laki-laki hanya $40,5 \% .^{7}$ Pada penelitian ini didapatkan bahwa perempuan lebih banyak mengalami gangguan kognitif daripada laki-laki. Hal ini dikarenakan jumlah perempuan lebih banyak dari laki-laki dalam penelitian ini. Apabila distribusi berdasarkan jenis kelamin seimbang antara laki-laki dan perempuan mungkin dapat memberikan hasil yang berbeda.

Distribusi usia responden pada tabel 2 didapatkan usia 40-59 paling banyak di temukan dengan persentase sebanyak $60 \%$ dan yang paling rendah pada usia $>80$ tahun dengan persentase hanya $5 \%$ dari total responden sebanyak 40 orang. Di Indonesia prevalensi hipertensi terusmenerus meningkat dan paling banyak meningkat pada usia $>50$ tahun sebanyak 20-30\%. Data dari pemeriksaan fungsi kognitif yang telah dilakukan, ditemukan bahwa usia 40-59 tahun lebih banyak mengalami gangguan kognitif. Pada penelitian yang dilakukan sebelumnya di RSUP Prof. Dr. R. D. Kandou malalayang didapatkan yang responden hipertensi terbanyak adalah pada umur 46-55 tahun. ${ }^{9}$

Pada Tabel 3 distribusi berdasarkan tingkat pendidikan didapatkan bahwa tingkat pendidikan SMA yang paling banyak dari 40 responden yaitu sebanyak 14 orang $(35 \%)$ dan yang paling sedikit ditemukan pada tingkat pendidikan SD hanya 6 orang (15\%). Sesuai dengan hasil pemeriksaan fungsi kognitif yang telah dilakukan bahwa yang mengalami gangguan fungsi kognitif paling tinggi yaitu pada tingkat pendidikan SMA dikarenakan jumlah responden pada tingkat SMA paling tinggi. Berbeda dari penelitian yang dilakukan sebelumnya di Indonesia pada wilayah tertentu ditentukan oleh tinggi rendahnya pendidikan dan yang paling banyak ditemukan dan terjadi pada pendidikan yang rendah yaitu sebesar $77,33 \%{ }^{7}$

Pada Tabel 4 distribusi berdasarkan tingkat pekerjaan didapatkan dari 40 responden, yang paling banyak adalah dengan pekerjaan sebagai IRT sebanyak 14 orang $(35 \%)$ dan paling sedikit dengan pekerjaan sebagai pensiunan sebanyak 2 
orang (5\%). Dari pemeriksaan fungsi kognitif yang telah dilakukan, yang paling banyak mengalami gangguan fungsi kognitif pada IRT.

Pada Tabel 5 didapatkan bahwa responden yang paling banyak ialah responden yang menderita hipertensi $\geq 5$ tahun $(77,5 \%)$ dan yang paling banyak mengalami penurunan fungsi kognitif adalah yang mengalami hipertensi $\geq 5$ tahun. Tidak jauh berbeda dengan penelitian Pandean dan Surachmanto ${ }^{9}$ yang pernah dilakukan di RSUP Prof. Dr. R. D. Kandou Manado bahwa penderita yang mengalami hipertensi lebih dari 5 tahun dapat berpengaruh pada fungsi kognitifnya.

\section{SIMPULAN}

Dari hasil penelitian fungsi kognitif yang telah dilakukan di Kelurahan Kakaskasen III Kecamatan Tomohon Utara pada 40 responden yang mempunyai riwayat hipertensi dengan menggunakan MMSE didapatkan gangguan kognitif sebesar $42,50 \%$ sedangkan dengan menggunakan CDT didapatkan gangguan kognitif sebesar $47,50 \%$.

\section{SARAN}

penelitian lebih lanjut sebaiknya dilakukan dengan jumlah sampel dan variabel yang lebih banyak dan luas dan penelitian harus terus dilakukan agar kiranya dapat membantu memberikan pengetahuan para praktisi medis mengenai dampak fungsi kognitif sendiri dan bagaimana untuk dapat mengatasinya. Perlu adanya informasi yang lebih luas kepada masyarakat-masyarakat umum mengenai dampak fungsi kognitif sendiri agar mereka dapat lebih mengetahui pentingnya pengetahuan mengenai fungsi kognitif sendiri. Kiranya untuk penderita dengan gangguan fungsi kognitif dengan riwayat hipertensi dapat selalu dipantau dan di berikan penangan yang komprehensif.

\section{DAFTAR PUSTAKA}

1. Bianti N. 2015. Risk Factors of Hypertension. Available online at juke.kedokteran.unila.ac.id/index.php /majority/article/download/602/606

2. Hou X. Urban-rural disparity of overweight, hypertension, undiagnosed hypertension, and untreated hypertension in China. Asia Pac J Public Health. 2008;20(2):159-69.

3. Kementerian Kesehatan Republik Indonesia. Riset Kesehatan Dasar 2013. Jakarta: Badan Penelitian Pengembangan Kesehatan Departemen Kesehatan Republik Indonesia. 2013.

4. Hendrie HC. Albert MS. Butters MA. Gao S, Knopman DS, Launer LJ, et al. The NIH Cognitive and Emotional Health Project: Report of The Critical Evaluation Study Committee. Alzheimers Dement. 2006;2(1):1232.

5. Herlina. Pengaruh Triterpen Total Pegagan Terhadap Fungsi Kognitif Belajar dan Mengingat pada Mencit Jantan Albino. Palembang: FMIPA Universitas Sriwijaya; 2010.

6. Taufik ES, Purwoko Y, Muhartomo H. 2014. Pengaruh hipertensi terhadap fungsi kognitif pada lanjut usia. Available from: http://eprints.undip.ac.id/44611/3/Ed win_22010110120099_Bab2KTI.pdf

7. Amalia DR. 2014. Hubungan hipertensi dengan fungsi kognitif. Available from:

http://etd.unsyiah.ac.id/baca/index.ph $\mathrm{p} ? \mathrm{id}=5179$ \&page $=31$

8. Kartikawati A. 2008. Prevalensi dan determinan hipertensi pada pasien puskesmas di Jakarta tahun 2007. Available from:t lib.ui.ac.id/file?file=digital/122551-S5407-Prevalensi\%20dan-HA.pdf

9. Pandean GV. Surachmanto EE. 2016. Hubungan hipertensi dengan fungsi kognitif di Poliklinik SMF Ilmu Penyakit Dalam RSUP Prof. Dr. R. D. Kandou Manado. Available from: ejournal.unsrat.ac.id/index.php/eclini c/article/download/12147/11728 